\title{
Ciprofloxacin-loaded polymeric nanoparticles incorporated electrospun fibers for drug delivery in tissue engineering applications
}

Citation for published version (APA):

Günday, C., Anand, S., Gencer, H. B., Munafò, S., Moroni, L., Fusco, A., Donnarumma, G., Ricci, C., Hatir, P. C., Türeli, N. G., Türeli, A. E., Mota, C., \& Danti, S. (2020). Ciprofloxacin-loaded polymeric nanoparticles incorporated electrospun fibers for drug delivery in tissue engineering applications. Drug Delivery and Translational Research, 10(3), 706-720. https://doi.org/10.1007/s13346-020-00736-1

Document status and date:

Published: 01/06/2020

DOI:

10.1007/s13346-020-00736-1

Document Version:

Publisher's PDF, also known as Version of record

\section{Document license:}

Taverne

Please check the document version of this publication:

- A submitted manuscript is the version of the article upon submission and before peer-review. There can be important differences between the submitted version and the official published version of record.

People interested in the research are advised to contact the author for the final version of the publication, or visit the DOI to the publisher's website.

- The final author version and the galley proof are versions of the publication after peer review.

- The final published version features the final layout of the paper including the volume, issue and page numbers.

Link to publication

\footnotetext{
General rights rights.

- You may freely distribute the URL identifying the publication in the public portal. please follow below link for the End User Agreement:

www.umlib.nl/taverne-license

Take down policy

If you believe that this document breaches copyright please contact us at:

repository@maastrichtuniversity.nl

providing details and we will investigate your claim.
}

Copyright and moral rights for the publications made accessible in the public portal are retained by the authors and/or other copyright owners and it is a condition of accessing publications that users recognise and abide by the legal requirements associated with these

- Users may download and print one copy of any publication from the public portal for the purpose of private study or research.

- You may not further distribute the material or use it for any profit-making activity or commercial gain

If the publication is distributed under the terms of Article $25 \mathrm{fa}$ of the Dutch Copyright Act, indicated by the "Taverne" license above, 


\title{
Ciprofloxacin-loaded polymeric nanoparticles incorporated electrospun fibers for drug delivery in tissue engineering applications
}

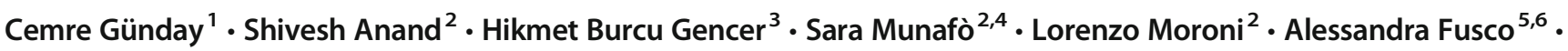 \\ Giovanna Donnarumma ${ }^{5,6}$. Claudio Ricci ${ }^{6}$ - Pinar Cakir Hatir ${ }^{3} \cdot$ Nazende Günday Türeli $^{1}$ - Akif Emre Türeli ${ }^{1}$. \\ Carlos Mota ${ }^{2} \cdot$ Serena Danti ${ }^{4,6}$
}

Published online: 25 February 2020

(C) Controlled Release Society 2020

\begin{abstract}
Presented work focuses on the development of biodegradable polymer nanoparticles loaded with antibiotics as drug delivery systems deposited on electrospun scaffolds for tissue engineering. The innovative ciprofloxacin-loaded poly(DL-lactide-coglycolide) NPs ensure a continuous slow release and high local concentration at the site of action for an optimal therapy. The local delivery of antibiotics as an integrated part of electrospun scaffolds offers an effective, safe, and smart enhancement supporting tissue regeneration. Presented data provides solid scientific evidence for fulfilling the requirements of local nano antibiotic delivery systems with biodegradability and biocompatibility for a wide range of tissue engineering applications, including middle ear tissues (e.g., tympanic membranes) which are subject to bacterial infections. Further characterization of such systems, including in vivo studies, is required to ensure successful transfer from lab to clinical applications.
\end{abstract}

Keywords Nanoparticles $\cdot$ Electrospinning $\cdot$ Stem cells $\cdot$ Immunomodulation $\cdot$ Regenerative medicine

\section{Introduction}

Cemre Günday and Shivesh Anand equally contributed to this research article.

Electronic supplementary material The online version of this article (https://doi.org/10.1007/s13346-020-00736-1) contains supplementary material, which is available to authorized users.

Nazende Günday Türeli

n.guenday@mjr-pharmjet.com

1 MJR PharmJet GmbH, Industriestr. 1B, 66802 Überherrn, Germany

2 MERLN Institute for Technology-Inspired Regenerative Medicine, Department of Complex Tissue Regeneration, Maastricht University, 6229 ER Maastricht, The Netherlands

3 Department of Biomedical Engineering, Istanbul Arel University, 34537 İstanbul, Turkey

4 Department of Civil and Industrial Engineering, University of Pisa, 56122 Pisa, Italy

5 Department of Experimental Medicine, University of Campania "Luigi Vanvitelli", 80138 Naples, Italy

6 Consorzio Interuniversitario Nazionale per la Scienza e Tecnologia dei Materiali (INSTM), Florence, Italy
Nano drug delivery systems are being intensively investigated due to the increasing demand on safer, more effective, and lower-cost drug formulations. Nanomedicine has rapidly promoted the development of a large number of new-generation innovative products that reached clinics [1]. A variety of different approaches from polymeric to inorganic nanoparticles (NPs) and lipid to liposome based have been developed as nano drug carriers $[2,3]$. Among them, the (bio)polymerbased NP systems are highly accepted and have already shown clinical success. However, there remain several unresolved challenges in integrating these successful drug delivery systems with the emerging fields of regenerative medicine and tissue engineering (TE).

With the ability to repair damaged or defunct tissues, TE has evolved as a promising approach towards addressing the current lack of sufficient implantable tissues and organs. Introduced in the late 1980s, TE aims at applying the principles of engineering and life sciences to develop biological substitutes that can restore, maintain, or improve tissue functionality [4]. There are three key pillars identified for the application of TE-based approaches, which are (a) supporting scaffolds, (b) 
bioactive molecules, and (c) incorporation of cells. Among these, the development of relevant three-dimensional (3D) scaffolds has been deemed crucial for mimicking the native tissue architecture and properties [4]. Biofabrication has emerged as an essential toolkit for the automated generation of 3D constructs loaded with requisite bioactive molecules for replicating the tissue microenvironment [5]. These 3D biofabricated scaffolds laden with essential growth factors are then used to culture cells, before they can be grown into a full tissue and transplanted into the human body. Latest strategies, such as $3 \mathrm{D}$ bioprinting have even advocated the incorporation of cells during the fabrication process, but their discussion is beyond the scope of this work [6].

Electrospinning (ES) is a widely used biofabrication technique for manufacturing polymeric fibers within the range of native collagen fibrils $[7,8]$. Electrospun fibers, with both synthetic and natural polymers, have been reported to be excellent candidates for manufacturing tissue-engineered scaffolds for several applications, such as regeneration of the tympanic membrane [9, 10], skin [11], and cartilage [12], among other tissues. Many of these synthetic biodegradable polymers with non-toxic character have been found to be promoting superior cell attachment and proliferation, with modulated inflammatory response. Moreover, therapeutic molecules are also known to play a vital role in the regeneration of damaged tissues [13]. Tissue implants of electrospun fibers loaded with various drugs and/or biomolecules have been shown to enhance the regenerative properties by facilitating the local delivery of these entities [14-17]. However, the lack of a suitable microenvironment, for example, due to the presence of an infection on-site may affect the implants' biocompatibility and jeopardize their regenerative properties.

Electrospun scaffolds loaded with antibiotic nanoparticles, on the other hand, can offer several advantages [18], since they provide controlled and sustained release of antibiotics at effective concentration at local site to actively prevent infection and, eventually, the biofilm formation after implantation and during healing. Incorporating antibacterial agents in electrospun scaffolds might not only prevent infection during wound healing but also may prevent rejection of the implant due to minimized stress at microenvironment as a result of sustained and controlled release of the agent. Controlling the release kinetics of drug and biomolecules from the electrospun fibers is critical in regenerative tissue engineering $[15,19]$. Different methods have been used to incorporate antimicrobial agents in electrospun fibers during the ES process, including blending [6], coaxial ES [6], and emulsion ES [6], to provide controlled release of the agent [20]. All these strategies result in the encapsulation of the antibiotic within the electrospun fibers, where its release is directly dependent on the degradation of the polymeric nanofibers. These approaches usually employ a relatively fast degrading polymer to achieve a sustained release of the antibiotic [21-23]. However, several applications in TE, such as bone, cartilage, and tympanic membrane, often demand the use of polymers that could remain stable at least for a few months [24, 25]. Therefore, the abovementioned ES strategies might not be suitable for these applications. To address this issue, we have developed a co-ES/electrospraying setup to load antibiotic-loaded NPs on the surface of polymer scaffolds.

In this study, ciprofloxacin-loaded poly(DL-lactide-coglycolide) (PLGA) and poly ( $\varepsilon$-caprolactone) (PCL) NPs deposited on electrospun fibers are developed and characterized for their potential use in tissue engineering. These systems are aimed to have anti-inflammatory and antimicrobial activity with biocompatible drug delivery system character. The polymeric nanoparticles which are prepared from biocompatible and biodegradable polymers, like PLGA and PCL, have shown significant therapeutic potential to achieve controlled drug delivery [26-31]), where the drug release was modified by altering the psychochemical properties, and formulation components, as well as by optimizing different preparation techniques [32]. For this purpose, modified solvent evaporation-double emulsion water-in-oil-in-water (w/o/w) and nanoprecipitation approaches are evaluated for manufacturing ciprofloxacinloaded PLGA and PCL nanoparticles using continuous microjet reactor technology [26, 33, 34]. Nanoparticulate systems are designed to provide prolonged delivery in a controlled way to enhance therapy and increase patient compliance.

This work proposes the use of a co-electrospinning/ electrospraying approach as the suitable biofabrication technique to evaluate the incorporation of ciprofloxacinencapsulated NPs on tissue-engineered scaffolds. Poly(ethylene oxide terephthalate)/poly(butylene terephthalate) (PEOT/PBT) copolymer was used to construct the NPloaded electrospun scaffolds. Two independent strategies were investigated for a homogeneous deposition of the NPs.

To our best knowledge, none of the current devices clinically employed for regenerative medicine and TE are based on biomimetic features with nanoscale resolution, and none of them rely on the application of nanotechnology. We aim developing and demonstrating the proof of concept for novel implants combining nanomedicine and tissue engineering in a single multifunctional platform in order to overcome the current therapy bottlenecks. We present the potential use of electrospun scaffolds that enable safe and efficient tissue engineering with a low risk of adverse events and rejections due to reduced bacterial infection and biofilm owing to local antibiotic delivery via embedded innovative, biodegradable NP formulations.

\section{Materials and methods}

\section{Materials}

PLGA (5050 DLG 4A, $52 \mathrm{kDa}$ ) and poly( $\varepsilon$-caprolactone) (100 CL 4E-HD, $31 \mathrm{kDa}$ ) were both obtained from Evonik 
(Birmingham, AL, USA). Ciprofloxacin was purchased from Sigma-Aldrich (Steinheim, Germany), and ciprofloxacin $\mathrm{HCl}$ was purchased from AppliChem (Darmstadt, Germany). Sorbitan monooleate $\left(\operatorname{Span}^{\circledR}{ }^{\circledR}\right.$ 80; Guangdong Runhua Chemistry Co., Ltd., China), polyethylene glycol sorbitan monooleate (Tween ${ }^{\circledR} 80$; VWR, Darmstadt, Germany), polyvinyl alcohol (PVA, Mowiol ${ }^{\circledR}$ 4-98; Sigma-Aldrich, Steinheim, Germany), and D-alpha-tocopheryl polyethylene glycol 1000 succinate (Vitamin E TPGS; Gustav Parmentier $\mathrm{GmbH}$, Frankfurt, Germany) were used as surfactants. Oleic acid (Ph. Eur.), acetone, chloroform, hexafluoroisopropanol, and ethyl acetate were purchased from VWR (Darmstadt, Germany). Copolymer of PEOT/PBT was kindly provided by PolyVation B.V. (Groningen, The Netherlands). Being a segmented random block copolymer, its soft, hydrophilic PEOT segments are physically cross-linked by the hard, semi-crystalline PBT segments. The selected composition of PEOT/PBT for this study was 300PEOT55PBT45, where following an $a$ PEOT $b$ PBT $c$ classification, the number 300 signifies the molecular weight ( $\mathrm{Mw}, \mathrm{g} / \mathrm{mol}$ ) of the initial PEG blocks used in the copolymerization, whereas 55/45 are the weight ratios of PEOT and PBT blocks, respectively.

Human mesenchymal stem cells (hMSCs) were supplied from Merck Millipore S.A.S. (Burlington, MA, USA). Human immortalized dermal keratinocyte HaCaT, L-glutamine, penicillin, streptomycin, and fetal calf serum were purchased from Invitrogen (Carlsbad, CA, USA). Fetal bovine serum (FBS) and LIVE/DEAD kit were bought from Thermo Fisher Scientific (Waltham, MA, USA). Resazurin, Dulbecco's minimal essential medium (DMEM), phosphatebuffered saline (PBS), gentamycin sulfate, and Triton-X were supplied by Sigma (Milan, Italy). Bacteria Staphylococcus aureus (ATCC 6538) and Pseudomonas aeruginosa (ATCC 9027), as well their culture substrates (tryptic soy (TS) agar and Luria-Bertani (LB) agar, respectively) were obtained from ATCC (Manassas, VA, USA).

\section{NP preparation with nanoprecipitation method}

Bench-top nanoprecipitation method was modified after Torge et al. [35]. Briefly, $4 \mathrm{mg} / \mathrm{ml} \mathrm{PCL}$ or PLGA and $1.5 \mathrm{mg} / \mathrm{ml} \mathrm{Span}$ $80^{\circledR}$ solution in acetone was mixed with $165 \mu \mathrm{l}$ of $48.5 \mathrm{mg} / \mathrm{ml}$ ciprofloxacin solution in oleic acid to obtain the solvent system. Blank nanoparticles were prepared without ciprofloxacin, by only adding oleic acid into the solvent. Ciprofloxacincontaining solutions were protected from light; $0.15 \%$ aqueous Tween 80 solution was used as a non-solvent system for both PLGA and PCL NP preparations. Solvent system was transferred on the non-solvent system at 1:2 v/v ratio under continuous stirring. NPs were protected from light.

NP preparations via the nanoprecipitation method by utilizing continuous microjet reactor (MJR) technology was performed at $25{ }^{\circ} \mathrm{C}$ where solvent delivering capillaries and the
MJR were immersed into a water bath in order to control the system temperature. Solvent system and non-solvent system were delivered to the MJR at 1:2 flow rate ratio at $180^{\circ}$ angle by using Smartline S100 pumps (Knauer, Munich, Germany). Since nitrogen gas was not employed, fourth opening was sealed.

Removal of organic phase and purification was achieved by continuous flow filtration (CFF) where modified polyethersulfone (mPES) MidiKros ${ }^{\circledR}$ 0.5-mm hollow fiber filters with a $10 \mathrm{kDa}$ MWCO and a surface area of $235 \mathrm{~cm}^{2}$ (Spectrum; Repligen Europe B.V., Breda, Netherlands) were used. For biofabricated electrospun scaffolds containing NPs, ciprofloxacin-loaded NPs were concentrated 5-fold by using CFF to obtain higher ciprofloxacin concentrations during optimization of biofabrication of the scaffolds.

For preparation of metallic core loading in PLGA via nanoprecipitation, please refer to supplementary materials.

\section{PLGA NP preparation with modified w/o/w method}

Organic solvent-containing phase was prepared by dissolving PLGA in ethyl acetate to obtain $20 \mathrm{mg} / \mathrm{ml}$ of polymer concentration. Thereafter, ciprofloxacin $\mathrm{HCl}(35 \mathrm{mg} / \mathrm{ml})$ dissolved in an aqueous solution of $1 \%$ PVA was emulsified with PLGA solution at $1: 3 \mathrm{v} / \mathrm{v}$ ratio. Emulsification was performed with a WiseTis ${ }^{\circledR}$ HG-15A homogenizer at 27,000 rpm for $30 \mathrm{~s}$. Directly after primary emulsion was obtained, second emulsification was performed at 27,000 rpm for $1 \mathrm{~min}$, where aqueous $2 \%$ Vitamin E TPGS solution was used as dispersing phase at $1: 5 \mathrm{v} / \mathrm{v}$ ratio. The final formulation was obtained by adding on an aqueous solution of $1 \%$ TPGS solution under moderate stirring at $1: 2 \mathrm{v} / \mathrm{v}$ ratio. NPs were protected from light during evaporation of organic phase under stirring. Blank NPs were prepared without ciprofloxacin $\mathrm{HCl}$, only with $1 \%$ PVA solution in the primary emulsion.

NP preparations by utilizing MJR technology was performed at $25{ }^{\circ} \mathrm{C}$ where solvent delivering capillaries and the MJR were immersed into a water bath in order to control the system temperature. For preparation of the primary emulsion, inner phase and organic solvent were delivered to the MJR at 1:3 flow rate ratio at $180^{\circ}$ angle by using Smartline S100 pumps (Knauer, Munich, Germany). Then, the MJR was run in loop mode for 10 cycles. Primary emulsion was mixed with outer phase by MJR at 1:5 flow rate ratio and homogenized at loop mode for 20 cycles. Since nitrogen gas was not employed, fourth opening was sealed. Double emulsion was added on $1 \%$ TPGS solution under moderate stirring.

Removal of organic phase, purification, and, where necessary, concentration were achieved as stated for the nanoprecipitation method.

For preparation of metallic core (gold and iron oxide NP) loading in PLGA via the modified w/o/w method, please refer to supplementary materials. 


\section{Physicochemical characterization of nanoparticles}

The methods for particle size distribution, zeta potential determination, ciprofloxacin quantification, encapsulation efficiency (EE) \%, and drug loading (DL) \% determination, as well as in vitro release testing, are provided in supplementary materials.

The feasibility testing method of down processing of NPs into scaffolds is also provided in supplementary materials.

\section{Electrospinning and electrospraying of the scaffolds}

300PEOT55PBT45 was used as the selected PEOT/PBT composition. A polymeric solution with $18 \%(\mathrm{w} / \mathrm{v})$ of 300PEOT55PBT45 was prepared in a 70:30 solvent mixture of chloroform and hexafluoroisopropanol (HFIP), respectively. In the first approach, prefabricated electrospun meshes were immersed in NP solutions and left overnight at room temperature. The second approach, being the more sophisticated of the two, implemented a co-ES/electrospraying (co$\mathrm{ES} / \mathrm{E}$ ) setup for simultaneous deposition of NPs during the ES process. The ES parameters for PEOT/PBT were maintained consistent for both the immersion and co-E/E approaches. A voltage of $20 \mathrm{kV}$ was applied between the spinneret and grounded mandrel $($ diameter $=20 \mathrm{~cm})$ rotating at $150 \mathrm{rpm}$. The flow rate for polymer extrusion was set at $0.9 \mathrm{ml} / \mathrm{h}$ with a working distance of $10 \mathrm{~cm}$. In addition to these, for the co-E/ E approach, a supplementary spinneret was installed perpendicularly for the simultaneous electrospraying of NP solution. The flow rate for NP extrusion was optimized at $1.5 \mathrm{ml} / \mathrm{h}$ for a working distance of $5 \mathrm{~cm}$.

Volatile solvent systems employing EtOH and $\mathrm{MeOH}$ were investigated for the predominantly aqueous NPs to enhance its rate of evaporation during electrospraying. A metallic core (gold and iron) was introduced within the NPs (see supplementary material for further details) to ameliorate their imaging under scanning electron microscope (SEM) and transmission electron microscope (TEM). Finally, Au-PLGA NPs in water was used as a proof of concept for this study.

The adhesion of PLGA NPs deposited on top of the electrospun fibers was evaluated for $24 \mathrm{~h}, 48 \mathrm{~h}$, and $72 \mathrm{~h}$. Samples were immersed in Milli-Q water at room temperature, collected, dried, and analyzed by SEM.

\section{In vitro characterization}

\section{Cytotoxicity tests}

Cytotoxicity tests were carried out by using hMSCs and $\mathrm{HaCaT}$ cell line. The different nanoparticles, both plain and ciprofloxacin loaded, including ciprofloxacin powders (base and $\mathrm{HCl}$ ) and untreated cells as controls, were used. All cell culture studies were carried out in a humidified incubator at $37{ }^{\circ} \mathrm{C}$ in air and $5 \% \mathrm{CO}_{2} / 95 \%$ air environment.

$\mathrm{HaCaT}$ cells were seeded at 250,000 cells/well in 12-well culture plates added with DMEM supplemented with $1 \%$ PenStrep, $1 \%$ glutamine, and $10 \%$ fetal calf serum for $24 \mathrm{~h}$. PLGA produced with microprecipitation (PLGA-microP); PLGA produced with water-in-oil-in-water emulsion (PLGA-wow), PCL, and blank NPs, as well as ciprofloxacin powders; and different dilutions obtained from $200 \mu \mathrm{g} / \mathrm{ml}$ stock solutions were administered to the cells, namely 1:2, 1:5, 1:10, 1:100, $1: 1000$, and $1: 10,000$, leading to $100 \mu \mathrm{g} / \mathrm{ml}, 40 \mu \mathrm{g} / \mathrm{ml}$, $20 \mu \mathrm{g} / \mathrm{ml}, 2 \mu \mathrm{g} / \mathrm{ml}, 0.2 \mu \mathrm{g} / \mathrm{ml}$, and $0.02 \mu \mathrm{g} / \mathrm{ml}$ concentrations, respectively.

HMSCs were seeded at a 25,000 cells/well in 24-well culture plates and cultured using $1 \mathrm{ml} /$ well of DMEM low glucose supplemented with $2 \mathrm{mM}$ L-glutamine, $100 \mathrm{IU} / \mathrm{ml}$ penicillin, $100 \mathrm{mg} / \mathrm{ml}$ streptomycin, and $10 \%$ heat-inactivated FBS for $48 \mathrm{~h}(n=3)$. The final ciprofloxacin amount in each sample treated with ciprofloxacin-loaded nanoparticles and powder was $20 \mu \mathrm{g} / \mathrm{ml}$.

Resazurin dye test was used to assess the metabolic activity of $\mathrm{HaCaT}$ cells and hMSCs at their endpoints and was performed under UV-vis spectrophotometry. Briefly, resazurin was dissolved in PBS at $0.5 \mathrm{mg} / \mathrm{ml}$ and sterile filtered to obtain a stock solution. At the endpoint, the culture media were removed and replaced with culture media conditioned with resazurin and let react for $3 \mathrm{~h}$ in incubator. Resazurin turns from blue into purple-pink as a consequence of cellular reduction. After, the supernatant was removed and read in a plate reader (Victor 3; PerkinElmer, Waltham, MA, USA) using a double wavelength reading (at $570 \mathrm{~nm}$ and $600 \mathrm{~nm}$ ). The percentage of dye reduction with respect to controls was calculated by taking into account the molar extinction molar coefficients of the dye at the two wavelengths.

For $\mathrm{HaCaT}$ cells, the samples were assayed in duplicate $(n=2)$ against negative controls (samples without cells) and data are reported as average.

For hMSCs, the samples were assayed in triplicate $(n=3)$ and each sample was run 3 times. The absorbance data were normalized positive controls (untreated cells), and data were given as mean \pm standard deviation. Statistical analysis was performed for different subgroups using Student's $t$ test for independent samples. Statistical significance was assessed for $p$ values $<0.05$ by taking into account Bonferroni's correction.

At the endpoint, LIVE/DEAD assay was used to specifically identify dead hMSCs under fluorescence microscopy (Nikon Ti, Tokyo, Japan) equipped with a digital camera. Briefly, $2 \mu \mathrm{M}$ ethidium homodimer 1 in PBS was added to the cells, incubated for $30 \mathrm{~min}$ in incubator, and analyzed under TRITC. Micrographs were acquired for each group at $\times 20$ magnification.

For evaluating the cytocompatibility of electrospun scaffolds with and without ciprofloxacin-loaded PLGA 
nanoparticles, hMSCs were seeded (250,000 cells/scaffold) and cultured up to 8 days. Two time points (day 1 and day 8 ) were chosen for assessing the growth and proliferation of the seeded cells, which was performed by staining the actin filaments of the cells using Alexa Fluor ${ }^{\mathrm{TM}} 488$ phalloidin (Thermo Fisher Scientific, Waltham, MA, USA), and nuclei using 4,6-diamideino-2-phenylindole dihydrochloride (DAPI; Sigma-Aldrich, St. Louis, MO, USA). The 1:100 and 1:1000 dilutions of the reagents were used, respectively.

\section{Bacterial activity tests}

Strains of S. aureus and P. aeruginosa were grown overnight in the appropriate culture media. The broth cultures obtained after overnight incubation were diluted at a concentration of 0.5 O.D., and $100 \mu \mathrm{l}$ of each was plated on agar medium with the help of a swab. Following sowing, holes were drilled on the plates in which $100 \mu \mathrm{l}$ of each substance was added at different dilutions, namely undiluted (T.Q.), 1:10, 1:100, $1: 500$, and $1: 1000$, leading to $200 \mu \mathrm{g} / \mathrm{ml}, 20 \mu \mathrm{g} / \mathrm{ml}$, $2 \mu \mathrm{g} / \mathrm{ml}, 0.4 \mu \mathrm{g} / \mathrm{ml}$, and $0.2 \mu \mathrm{g} / \mathrm{ml}$ concentrations, respectively. An antibacterial activity is revealed by the presence of a transparent zone around the holes, due to the inhibition of bacterial growth. The diameters of the zones were measured and compared after $18 \mathrm{~h}$ of inoculation.

\section{Bacterial adhesiveness and internalization assays}

For adhesiveness assay, semi-confluent monolayers of $\mathrm{HaCaT}$ cells ( 80,000 cells in 48 -well plate) were grown overnight in DMEM, washed, and infected with exponentially growing $S$. aureus or $P$. aeruginosa with or without samples at $37^{\circ} \mathrm{C}$ in $5 \% \mathrm{CO}_{2}$ for $2 \mathrm{~h}$.

At the end of this time, infected monolayers were washed three times with PBS medium to remove non-adherent bacteria. The total number of cell-associated bacteria was determined by lysing the monolayers with $0.1 \%$ Triton X-100. Solubilized bacteria were counted (colony-forming units (CFUs)) by spreading serial dilutions on TSA or LB agar plates, respectively, and incubating at $37{ }^{\circ} \mathrm{C}$ overnight. Adhesion efficiency was calculated as the ratio of the number of cell-associated bacteria and the number of bacteria used to infect cell monolayers.

In the internalization assay, the cells, infected as previously described, were extensively washed and further incubated for $1.5 \mathrm{~h}$ with fresh medium supplemented with gentamicin sulfate $(250 \mu \mathrm{g} / \mathrm{ml})$ in order to kill extracellular bacteria. At the end of this time, monolayers were washed with PBS, lysed with $0.1 \%$ Triton $\mathrm{X}-100$, serially diluted, and plated on LB agar to quantify viable intracellular bacteria $(\mathrm{CFU} / \mathrm{ml})$. The efficiency was calculated as the ratio of the number of cellinternalized bacteria and the number of bacteria used to infect the cell monolayers.

\section{Results}

\section{Physicochemical characterization of nanoparticles}

Blank NPs prepared by both modified w/o/w and nanoprecipitation methods via bench-top approach were smaller than $250 \mathrm{~nm}$ with moderate PDI values $<0.2$, whereas ciprofloxacin-loaded bench-top NPs were slightly larger in size with PDI values $<0.25$. MJR is a micromixer with confined impinging jet principle, where NPs are formed under controlled process conditions. Microvolume mixing at short mixing times leads to narrow particle size distributions (thus, lower PDI values) owing to continuous mixing in a microvolume [26, 34]. Indeed, this was observed for all cases, where PDI values for both blank and ciprofloxacin-loaded particles were $<0.15$ regardless of the employed manufacturing method. All formulations showed negative zeta potential (Table 1). Optimization studies revealed that MJR process parameters (flow rate, temperature, and pressure) had a significant effect on the particle size of ciprofloxacin-loaded PLGA and PCL NPs regardless of the employed method. Furthermore, the difficulties in scale-up are overcome by using a microjet reactor for continuous production with easily controllable parameters and reproducible results [36-38], whereas EE \% and DL \% were dominantly affected by formulation properties (drug:polymer ratio and solvent:non-solvent ratio). As the drug:polymer and solvent:non-solvent ratios decreased, the EE \% increased but the particle size was not significantly affected. Additionally, in order to enhance drug loading, oleic acid was used as co-solvent for dissolving ciprofloxacin $[35,39]$. Furthermore, ciprofloxacin has amine and carboxylic acid functional groups, which can interact with oleic acid by forming counter ion complexes [40]. Indeed, EE $\%$ of ciprofloxacin-loaded PLGA particles prepared by double emulsion method was determined as $60.7 \%(n=3)$, whereas ciprofloxacin-loaded PCL NPs had $82.7 \%$ EE (Fig. 2). By analyzing both permeate and retentate after centrifuging the samples with Macrosep ${ }^{\circledR}$ centrifugal device, the mass balance showed that there was no loss due to entrapment or deposition on the membrane. Additionally, ciprofloxacin solution was used as control for the filter compatibility testing to conclude that the ciprofloxacin did not show any interaction with the centrifugal device.

Particles were shown to be stable after 30 days of stability studies in room temperature as shown in Figs. 1 and 2. Longterm stability studies are ongoing.

\section{Release study}

Ciprofloxacin was released from PLGA-wow over $24 \mathrm{~h}$ following the Korsmeyer-Peppas kinetic model [41], which indicated anomalous release $(n=0.6)$. Anomalous release from PLGA is defined by Fick's diffusion followed by polymer- 
Table 1 Physicochemical characterization of NPs

\begin{tabular}{|c|c|c|c|c|c|c|c|c|c|c|c|c|c|c|c|c|}
\hline & \multicolumn{8}{|c|}{ Nanoprecipitation } & \multicolumn{8}{|c|}{ Double emulsion/solvent evaporation method } \\
\hline & \multicolumn{4}{|c|}{ Bench-top } & \multicolumn{4}{|l|}{ MJR } & \multicolumn{4}{|c|}{ Bench-top } & \multicolumn{4}{|l|}{ MJR } \\
\hline & $\begin{array}{l}\text { PS } \\
(\mathrm{nm})\end{array}$ & PDI & $\begin{array}{l}\mathrm{ZP} \\
(\mathrm{mV})\end{array}$ & $\begin{array}{l}\mathrm{EE} \\
(\%)\end{array}$ & $\begin{array}{l}\text { PS } \\
(\mathrm{nm})\end{array}$ & PDI & $\begin{array}{l}\mathrm{ZP} \\
(\mathrm{mV})\end{array}$ & $\begin{array}{l}\mathrm{EE} \\
(\%)\end{array}$ & $\begin{array}{l}\text { PS } \\
(\mathrm{nm})\end{array}$ & PDI & $\begin{array}{l}\mathrm{ZP} \\
(\mathrm{mV})\end{array}$ & $\begin{array}{l}\mathrm{EE} \\
(\%)\end{array}$ & $\begin{array}{l}\text { PS } \\
(\mathrm{nm})\end{array}$ & PDI & $\begin{array}{l}\mathrm{ZP} \\
(\mathrm{mV})\end{array}$ & $\begin{array}{l}\mathrm{EE} \\
(\%)\end{array}$ \\
\hline Blank PLGA NPs & 105.3 & 0.152 & -34.6 & - & 99.6 & 0.089 & -34.9 & - & 242.5 & 0.186 & -33.2 & - & 215.6 & 0.102 & -38.4 & - \\
\hline $\begin{array}{l}\text { Ciprofloxacin-loaded } \\
\text { PLGA NPs }\end{array}$ & 108.6 & 0.179 & -30.5 & 60.7 & 102.2 & 0.075 & -28.6 & 64.4 & 226.2 & 0.211 & -30.8 & 72.4 & 222.5 & 0.115 & -32.2 & 74.1 \\
\hline Blank PCL NPs & 209.0 & 0.079 & -48.2 & - & 195.4 & 0.034 & -47.3 & - & & & & & & & & \\
\hline $\begin{array}{l}\text { Ciprofloxacin-loaded } \\
\text { PCL NPs }\end{array}$ & 247.8 & 0.100 & -45.9 & 82.7 & 200.3 & 0.048 & -44.3 & 85.9 & & & & & & & & \\
\hline
\end{tabular}

$P S$ particle size, $P D I$ polydispersity index, $Z P$ zeta potential, $E E$ encapsulation efficiency

driven release. Similarly, to PLGA NPs, no initial burst release was observed for PCL NPs ( $<30 \%$ within the first $1 \mathrm{~h})$. On the other hand, ciprofloxacin release from PCL reached ca. $60 \%$ after $24 \mathrm{~h}$ and the release was completed in 2 weeks $(94.6 \%$, data not shown). No burst release was observed ( $<30 \%$ within the first $1 \mathrm{~h}$ ). Slower release kinetics from the PCL NPs is possibly due to the interaction of ciprofloxacin with oleic acid. Results provided as an average cumulative released amount of ciprofloxacin as percentage over time are depicted in Fig. 3.

\section{Biofabrication of NP-loaded electrospun scaffolds}

Electrospinning has emerged as an essential biofabrication strategy for constructing polymeric fibers within the range of native collagen fibrils. Owing to its simple yet robust technology, electrospun scaffolds have been manipulated for several tissue engineering applications. However, following successful transplantation of these tissue-engineered grafts or organs, targeted delivery of antibiotics has remained a major challenge. In this study, the incorporation of drug-loaded NPs on electrospun scaffolds was investigated as a proof of concept using Au-PLGA NPs. The gold core was chosen over iron due to its more uniform morphology and distribution as observed under TEM (Fig. 4). Preliminary studies with volatile electrospraying solvent systems did not yield any improvement in the fiber morphology; therefore, water was chosen as the working solution for NPs. Finally, both modified w/o/ $\mathrm{W}$ and nanoprecipitation were evaluated as potential synthesis routes for the two incorporation strategies highlighted in the previous section.

The immersion strategy for double emulsion NPs demonstrated deposition of some spherical aggregates over the electrospun nanofibers, accompanied by a widespread film enveloping them (Fig. 5b). On the other hand, the same approach for nanoprecipitated NPs did not result in any film formation. However, these NPs were observed only in large clusters, randomly spread over the immersed scaffold (Fig. 5c).

A similar trend concerning the film was observed in the case of co-E/E approach. Surprisingly, it persisted for double emulsion NPs even during its simultaneous deposition (Fig. 5e). Different concentrations of NP solution were tested to get rid of the film, but without any success. However, in terms of the deposition efficacy, co-E/E fared far better than the immersion strategy. Comparatively smaller and more homogeneous NP aggregates were obtained for double
Fig. 1 Particle size and PDI measurements of ciprofloxacinloaded PLGA-wow, PCL, and concentrated PCL NPs during the stability study

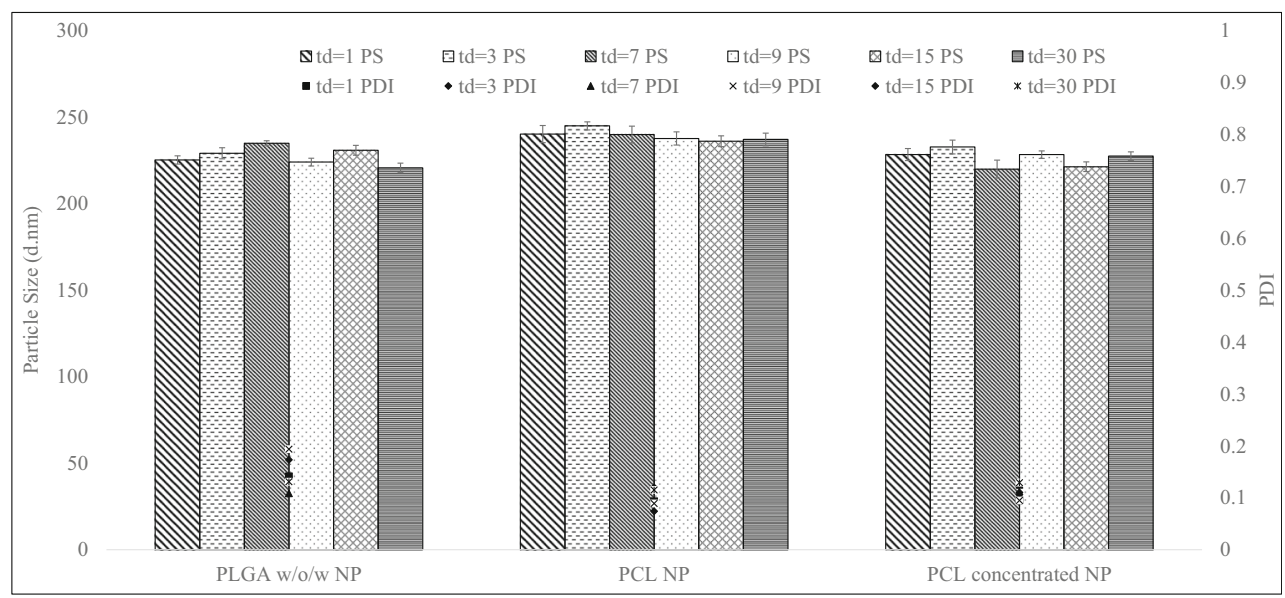


Fig. 2 Encapsulation efficiencies of ciprofloxacin-loaded PLGAwow and PCL NPs during the stability study

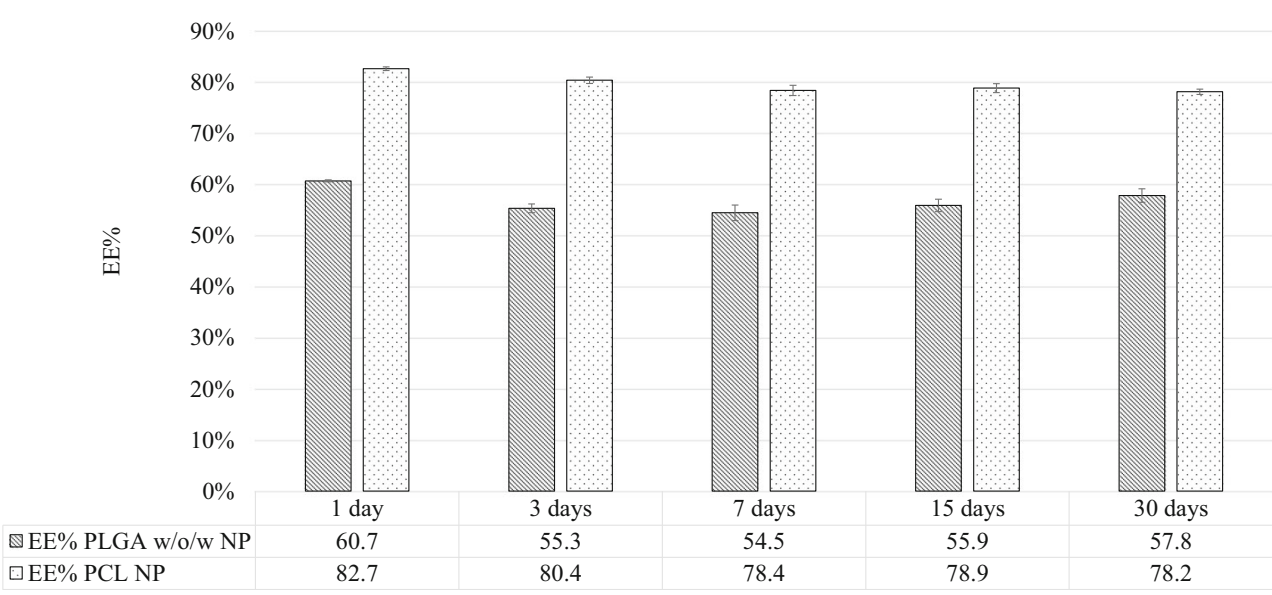

emulsion, whereas in the case of nanoprecipitated batch, individual NPs were deposited on the nanofibers across the entire scaffold, thereby emerging as the most optimum system for incorporation of drug-loaded NPs onto electrospun network (Fig. 5f).

Following the desired deposition, a successful adhesion was confirmed by submerging the NP-loaded scaffolds in Milli-Q water. SEM micrographs obtained at $24 \mathrm{~h}, 48 \mathrm{~h}$, and $72 \mathrm{~h}$ demonstrated a similar distribution of NPs over time (Fig. 6). The same experiment was also repeated with the double emulsion NPs to study its influence on the film. However, no change was observed.

\section{Down-processing feasibility}

In addition to the release from the encapsulation material, fiber composition containing antibiotic-loaded NPs for a controlled and sustained delivery should be carefully investigated. The diffusion of drug is directly influenced by the polymer properties. Therefore, the composition of nanofibers and the distribution of NPs over them are crucial for achieving desired drug release profiles. Additionally, the miscibility and stability of NPs during the biofabrication process also plays a critical role. To minimize the influence of an additional solvent enveloping the rotating collector ES PEOT/PBT, systems with higher volatility were investigated for the NPs. In order to ensure that the particles were intact and no drug release occurred upon dispersion in these new solvent systems, NPs were exposed and incubated with potential organic solvents that were applied for the preparation of drug-loaded nanofibers. Dose dumping studies showed that the particles were stable in all of the test solutions, where particle sizes were not affected and PDI values were comparable after $24 \mathrm{~h}$. As shown in Fig. 6, the PCL particles (Fig. 7a) and PLGA particles (Fig. 7c) showed similar profiles compare to control (NPs dispersed in water). On the other hand, for the concentrated PCL nanoparticles (Fig. 7b), the dose dumping test sample with EtOH addition showed a particle size change of approximately $35 \mathrm{~nm}$ after $24 \mathrm{~h}$ where all the other samples were shown to have similar particle size and PDI. Considering that most particle size measurements are associated with ca. $50 \mathrm{~nm}$ measurement uncertainty, one can neglect that change in hydrodynamic diameter.

Additionally, at predefined time points for determination of free ciprofloxacin, HPLC analysis was performed for all the samples of PCL and PLGA NPs where supernatants were injected following separation of the particles from released/ dumped free drug in triplets. Figure 8 a shows PCL
Fig. 3 Average cumulative released amount (\%) of ciprofloxacin in $24 \mathrm{~h}$ from PLGAwow and PCL NPs prepared via a microjet reactor

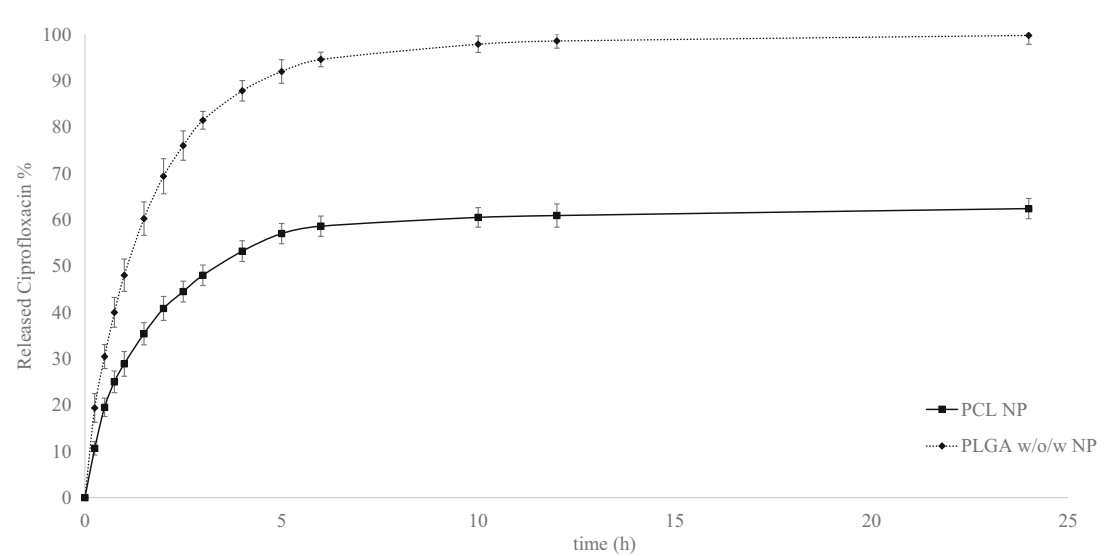



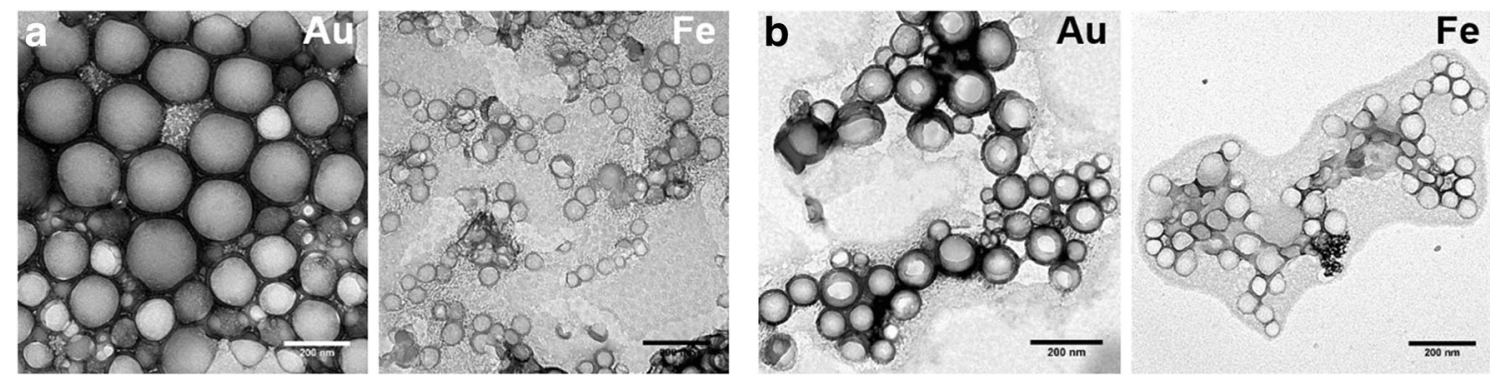

Fig. 4 TEM micrographs of PLGA NPs synthesized with metallic core (Au and Fe). a Modified w/o/w. b Nanoprecipitation

nanoparticles determined to have the highest amount of ciprofloxacin released in the presence of EtOH after $24 \mathrm{~h}$ where other solvents showed similar profiles compare to blank particles with water.

\section{In vitro characterization}

\section{Cytotoxicity}

The metabolic activity of $\mathrm{HaCaT}$ cells and hMSCs after administration of the NPs was investigated using the resazurin test. $\mathrm{HaCaT}$ cells were treated with different doses (ranging from $20 \mathrm{ng} / \mathrm{ml}$ to $100 \mu \mathrm{g} / \mathrm{ml}$ ) of ciprofloxacin-loaded (C+) PLGA-NPs, PLGA-wow and PCL NPs, blank (C-) NPs, and free drug ciprofloxacin for $24 \mathrm{~h}$. The results of cell metabolic activity are summarized in Fig. 9. Keratinocytes had a drop in their viability $(<50 \%)$ when treated with NPs at ciprofloxacin concentrations $\geq 20 \mu \mathrm{g} / \mathrm{ml}$, whereas ciprofloxacin concentrations $\leq 2 \mu \mathrm{g} / \mathrm{ml}$ were tolerated well and did not show any cytotoxicity. These results were consistent with the blank NPs of each particles applied at the same ciprofloxacin equivalent concentrations with the exception of blank PLGA-NPs, where no cytotoxic effect was exerted by blank NPs. These results lead to the assumption that the cytotoxicity was not depending on the ciprofloxacin concentration for PLGAwow and PCL NPs but any potential presence of cytotoxic components in NPs regardless of the preparation method or possibly the stress exerted to the cells by the presence of colloidal systems. Both assumptions were in accordance with the results obtained from free drug ciprofloxacin.

Based on the preliminary cytotoxicity test on $\mathrm{HaCaT}$ cells, the test concentration for hMSCs was assigned as $20 \mu \mathrm{g} / \mathrm{ml}$. hMSCs were exposed to NPs for $48 \mathrm{~h}$ in order to assess the possible cytotoxic effects. Figure 10 shows the results of resazurin test where the metabolic activity of ciprofloxacinloaded (C+) NPs was $79.0 \% \pm 5.6 \%$ for PCL, $84.2 \% \pm 4.3 \%$ for PLGA-NPs, and $84.9 \% \pm 4.9 \%$ for PLGA-wow. When applied at this concentration for a prolonged time $(48 \mathrm{~h})$, ciprofloxacin-loaded NPs showed statistically significant reduction with respect to the free ciprofloxacin base (Fig. 10ac). In each group, the presence of ciprofloxacin $(\mathrm{C}+)$ in NPs led to a decrease of metabolic activity, which was statistically significant in PLGA NPs $(p<0.01)$ and in PCL $(p<0.0001)$ (Fig. 10a, c) but not in PLGA-wow ( $p=0.05$, not significant) (Fig. 10b). It was concluded that ciprofloxacin-loaded NPs were not showing any cytotoxic effects on hMSCs when applied at $20 \mu \mathrm{g} / \mathrm{ml}$ concentrations even at prolonged exposure.

These findings were qualitatively confirmed by the ethidium homodimer 1 (DEAD) test under fluorescence microscopy (supplementary material Figure S1). More dead cells stained in red were visible in the C+ NP-treated hMSCs in comparison to $\mathrm{C}-\mathrm{NP}$-treated cells.

Phalloidin/DAPI staining of the hMSCs seeded on the electrospun scaffolds with ciprofloxacin-loaded PLGA NPs showed a homogeneous cell distribution and attachment, similar to that of the control on day 1 (Fig. 11). After 8 days in culture, the electrospun scaffolds containing ciprofloxacinloaded PLGA nanoparticles did not show any noticeable effect on cellular growth and proliferation, when compared with control.

Under the light of cytotoxicity tests, it was concluded that all of the prepared formulations were non-toxic and well tolerated even for concentrations up to 20-fold exceeding minimum inhibitory concentration (MIC) of ciprofloxacin against susceptible and resistant strains of $P$. aeruginosa $(0.25$ $0.99 \mu \mathrm{g} / \mathrm{ml})^{1}$.

\section{Bactericidal activity, adhesiveness, and invasion test}

The results of $S$. aureus inhibition showed that, in particular, at a concentration of $20 \mu \mathrm{g} / \mathrm{ml}$, all the ciprofloxacin-loaded NPs outperformed the free drug ciprofloxacin activity (see S2 A-F for details), where PLGA-wow and PCL-NPs showed slightly better bactericidal activity than PLGA-NPs (Fig. 12). PLGAwow was shown to be the most efficient NP against $S$. aureus at concentrations even at reduced concentrations of $2 \mu \mathrm{g} / \mathrm{ml}$ and $0.4 \mu \mathrm{g} / \mathrm{ml}$.

The results of $P$. aeruginosa inhibition as obtained with zone diameter measurements (see S3 A-F for details) after

\footnotetext{
${ }^{1}$ Breakpoint tables for interpretation of MICs and zone diameters, in the European Committee on Antimicrobial Susceptibility Testing, 2014.
} 

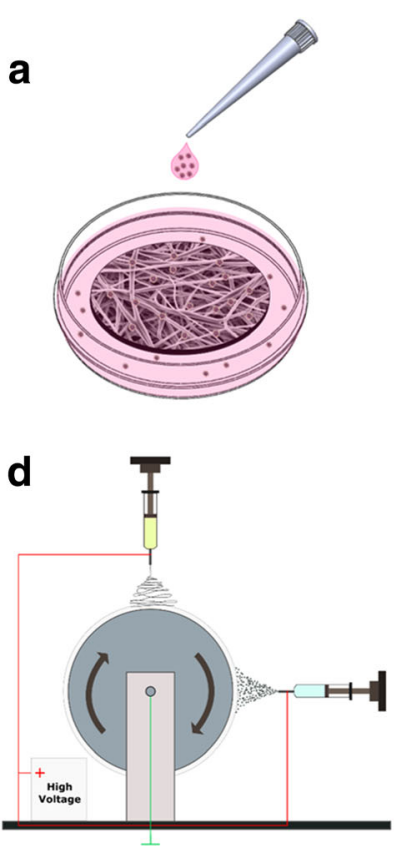

Fig. 5 Incorporation of antibiotic-loaded PLGA nanoparticles with simple immersion approach (a-c) and simultaneous co-electrospinning/ electrospinning approach $(\mathbf{d}-\mathbf{f})$. a, $\mathbf{d}$ Schematics representing the two
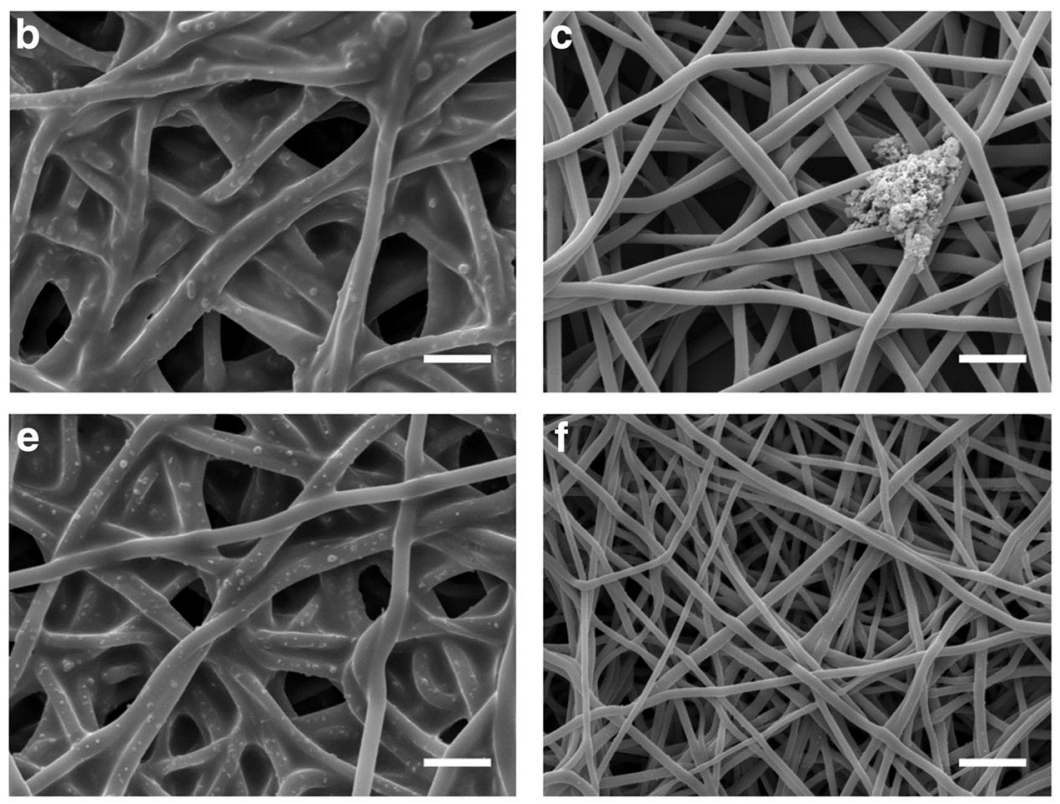

approaches. b, e Incorporation of wow NPs. c, f Incorporation of nanoprecipitated NPs. Scale bar $=5 \mu \mathrm{m}$ treatment with NPs are reported in Fig. 13. At all concentrations $(0.2-200 \mu \mathrm{g} / \mathrm{ml})$, the NPs did inhibit P. aeruginosa more effective than free ciprofloxacin. All the NPs did inhibit P. aeruginosa even at $2 \mu \mathrm{g} / \mathrm{ml}$ concentration, where free drug did not show effective inhibition. PLGA-wow and PCL still showed inhibitory effects even at $0.4 \mu \mathrm{g} / \mathrm{ml}$ concentration.

Blank NPs were tested as controls against both $S$. aureus and $P$. aeruginosa. Results indicated that blank NPs do not show any inhibitory effect (data not shown).

Finally, bacterial adhesion and invasion tests were performed by infecting $\mathrm{HaCaT}$ cells treated with the ciprofloxacin-loaded and blank NPs. The results showed that all ciprofloxacin-loaded NPs were able to hamper S. aureus adhesion (Fig. 14a), in particular PCL NPs showed the best inhibition percentage (-60\%). S. aureus invasion to $\mathrm{HaCaT}$ cells was inhibited by all of the tested ciprofloxacin-loaded NPs. The same observation was done for $P$. aeruginosa invasiveness and adhesion (about - 100\%) (Fig. 14b). Not surprisingly, blank NPs did not exert any effects, except for PCL NPs, which acted similarly to loaded NPs ( $-100 \%$ invasiveness and $-80 \%$ adhesion).

\section{Discussion}

In many tissue engineering applications, the role of the scaffold is to support healthy tissue regrowth, which comes after reconstructive surgery in a hostile microenvironment, in which inflammation is present, together with high probability of infection relapses. This is the case of tissues which usually
$24 \mathrm{~h}$

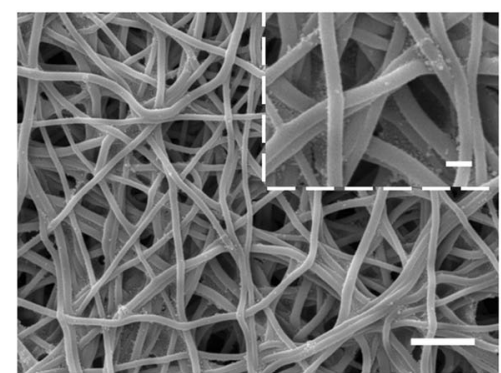

$48 \mathrm{~h}$

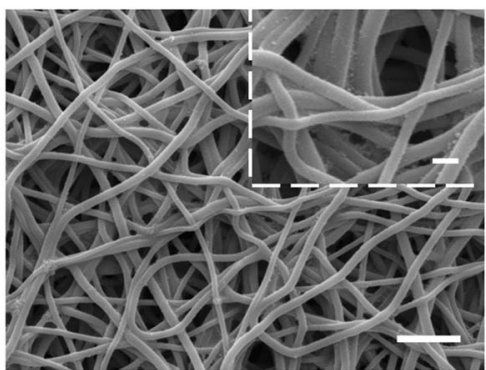

$72 \mathrm{~h}$

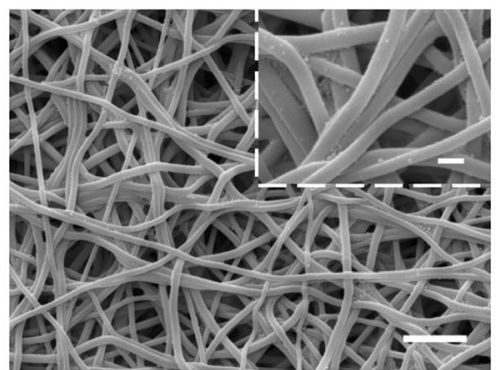

Fig. 6 SEM micrographs confirming the adhesion of PLGA NPs onto the electrospun fibers, when left immersed in Milli-Q water for $24 \mathrm{~h}, 48 \mathrm{~h}$, and $72 \mathrm{~h}$ in ambient conditions. Scale bars: normal $=5 \mu \mathrm{m}$, magnified inset $=1 \mu \mathrm{m}$ 
deal with microbiome and pathogens, like epithelia (e.g., ear, oral cavity, airways, skin, intestine, urinary tract). In order to enable a satisfactory regeneration of these tissues, it is of maximal importance to have non-contaminated tissue healing and tissue regeneration. Therefore, the possibility of having a combined platform enabling both antibiotic release and tissue regeneration offers remarkable advantages in engineering ear, airways, skin, and oral tissues, among others. S. aureus and $P$. aeruginosa are two common bacteria affecting the respiratory tract, which can overgrow, leading to chronic, recalcitrant infections caused by biofilm formation [42, 43]. The use of

a
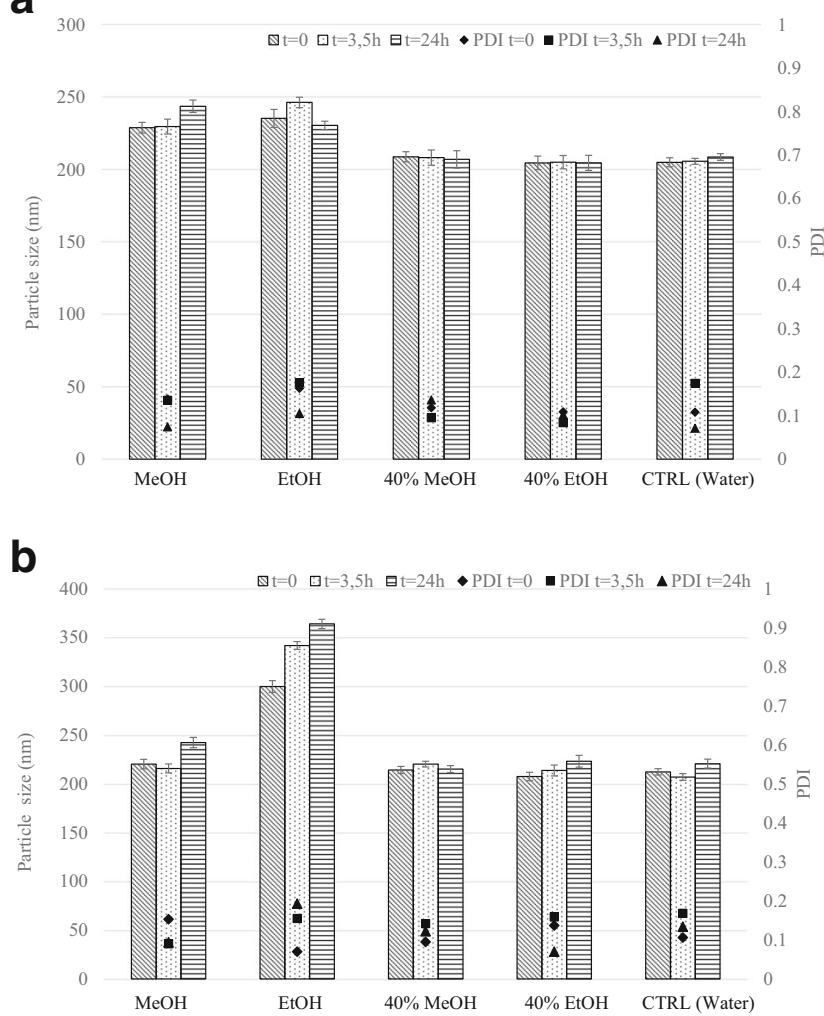

C

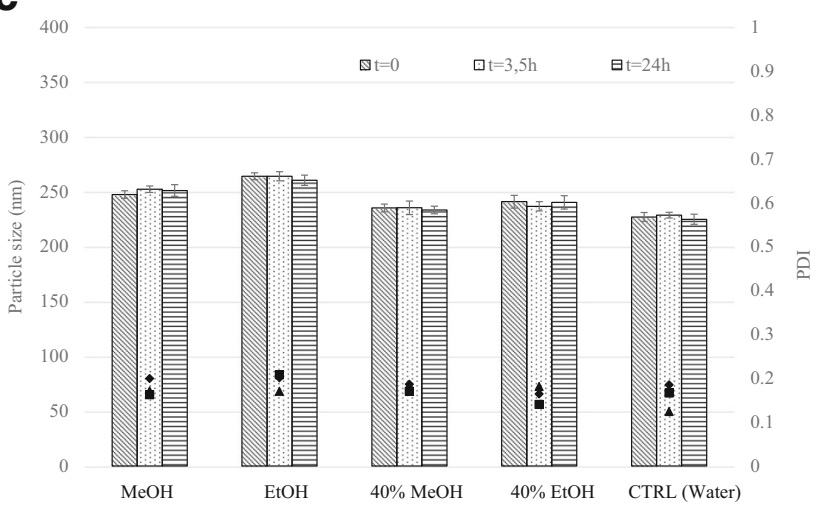

Fig. 7 Particle size and PDI measurements at time points of 0 h, $3 \mathrm{~h}, 5 \mathrm{~h}$, and $24 \mathrm{~h}$ of PCL nanoparticles (a), concentrated PCL nanoparticles (b), and PLGA-wow nanoparticles (c) for dose dumping test
NPs locally for promoting non-contaminated tissue healing and tissue regeneration offers many advantages such as (i) enhanced bioavailability, thus reduced doses, and potentially decreased side effects; (ii) sustaining the concentration at the site of action, thus potentially reduced application frequency; and (iii) achieving homogenous drug dose distribution across the tissue to heal.

In this study, we tested the safety and efficacy of NPs against these bacteria, where the proof-of-concept studies were realized by using employing different polymers as encapsulation materials for ciprofloxacin delivery. PLGAencapsulated pharmaceutical products are already at the market for some years and have been well characterized. Since PLGA possesses low toxicity, biocompatible character, and predictable biodegradation kinetics, it is extensively employed for drug delivery purposes [44]. PCL is a biodegradable polymer which belongs to aliphatic polyester family and has been extensively used for the development of wound dressings, contraceptive devices, fixation devices, and drug delivery systems [45-47]. Both of these polymers offer marketable drug delivery systems since they are very well characterized for safety and performance, and they are non-toxic polymers with biodegradable character. Indeed, careful selection of not only encapsulation material but also other formulation components (excipients) was justified with the results of in vitro characterization studies where the particles were shown to be safe and efficient against $S$. aureus and $P$. aeruginosa at potential clinical concentrations.

By utilizing continuous MJR, micromixing is achieved, resulting in narrow particle size distribution. The use of MJR increases the chance of the developed NPs to clinics not only due to easily scalable continuous process but also due to fact that manufacturing NPs under control conditions ensures high manufacturing quality with the same critical quality attributes, such as particle size, PDI, and drug loading, at every batch. Critical quality attributes of drug delivery systems might dictate physicochemical stability and are known to be also responsible for in vivo performance.

Results indicated that ciprofloxacin-loaded PLGA and PCL NPs exhibited the desired release properties to reach the therapeutic concentration (MIC of $0.25-0.99 \mu \mathrm{g} / \mathrm{ml}$ against susceptible and resistant strains of $P$. aeruginosa) within $24 \mathrm{~h}$ at the site of action to prevent any potential infection. Slower release kinetics from the PCL NPs in comparison to PLGA is possibly due to the interaction of ciprofloxacin with oleic acid. Ciprofloxacin is a zwitterionic substance with two ionizable groups: carboxyl and amine groups. Accordingly, its solubility depends on the physicochemical properties of the aqueous solvent used. However, oleic acid, unsaturated fatty acid, shows a lipophilic character and does not lead to ionization of ciprofloxacin, thus $\mathrm{pH}$-dependent solubility. On the other hand, it offers interaction sites to ciprofloxacin, e.g., through hydrogen bonding [35, 40]. By 
Fig. 8 Free ciprofloxacin concentration of PCL

nanoparticles (a) and PLGA-wow nanoparticles (b) during the dose dumping test at $t=0 \mathrm{~h}, 2 \mathrm{~h}, 4 \mathrm{~h}$, and $24 \mathrm{~h}$ a

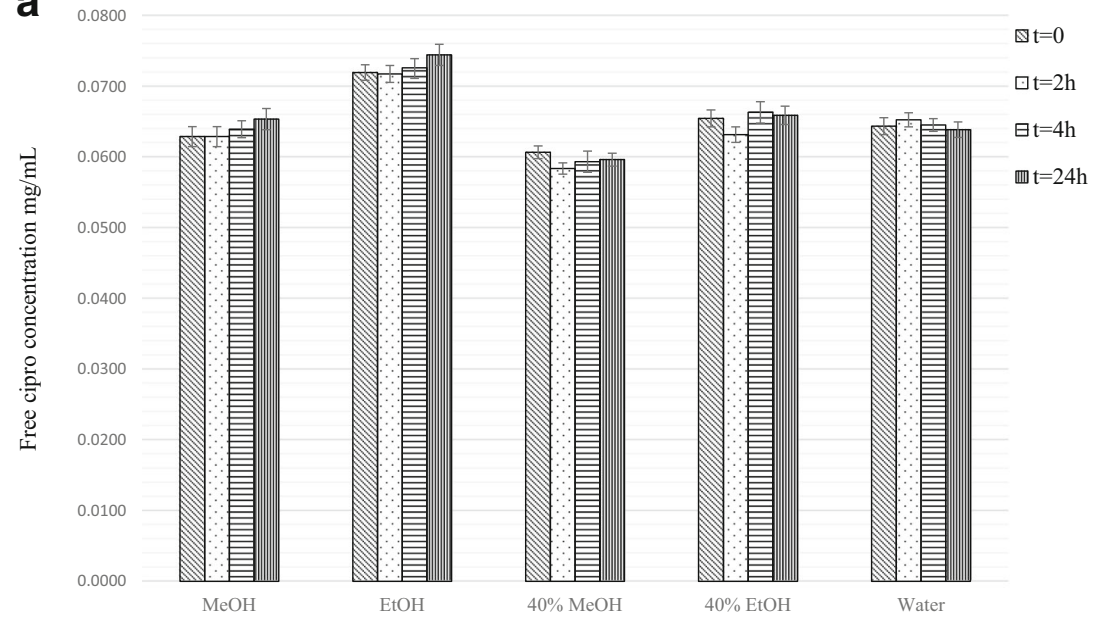

b

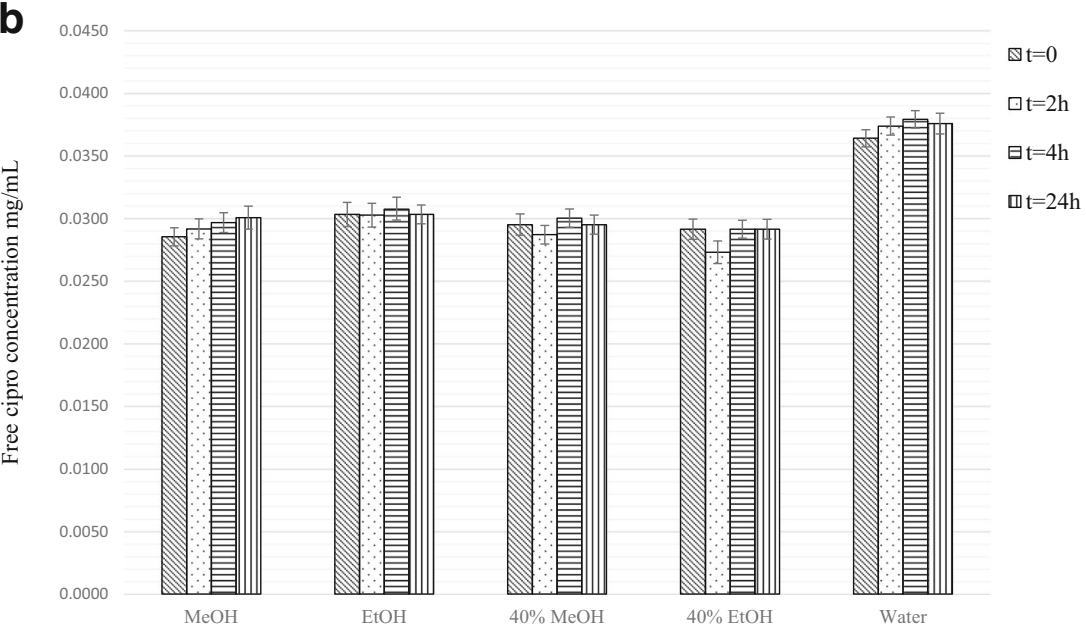

simultaneous deposition of PLGA and PCL NPs on the implants, the concentration at the site of action can be sustained since a biphasic release profile can be reached by physically mixing both particles: controlled release of the antibiotic from PLGA to reach the effective concentration at the site of action and slow releasing PCL NPs to sustain that concentration.
Fig. 9 Metabolic activity of $\mathrm{HaCaT}$ human keratinocytes after $24 \mathrm{~h}$, measured as resazurin reduction $\%$ with respect to negative controls, of different concentrations of ciprofloxacinloaded NPs (abbreviated as "C+") and blank NPs (abbreviated as "C -") $(n=2)$

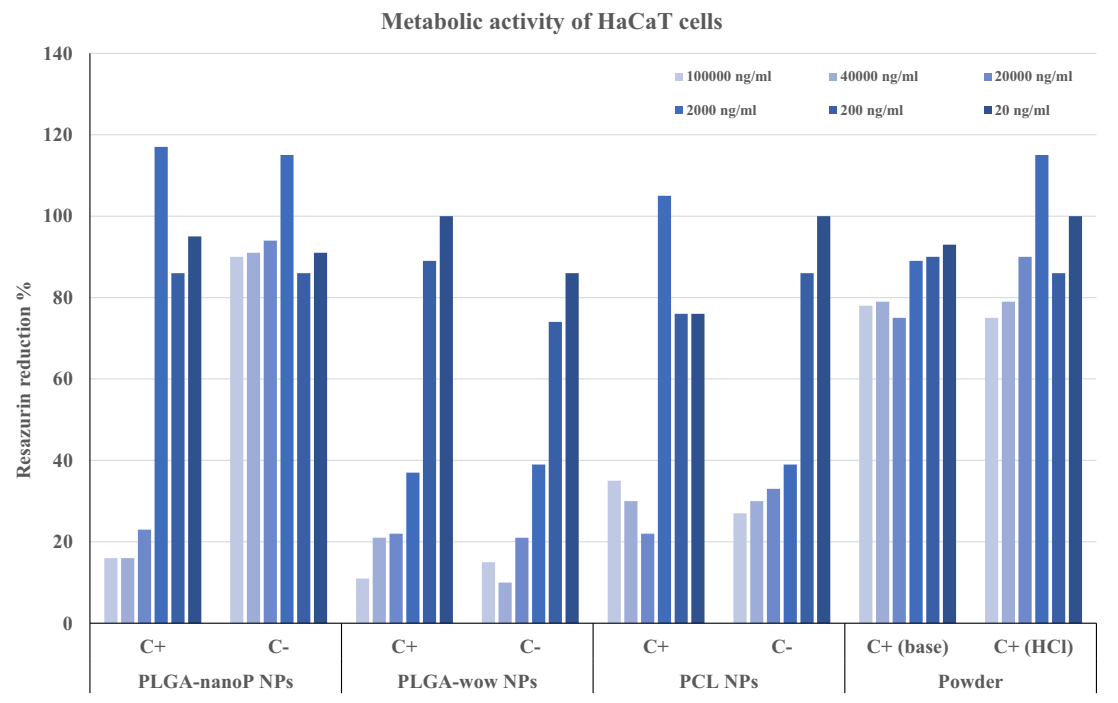


Fig. 10 Metabolic activity of hMSCs after $48 \mathrm{~h}$, measured as resazurin reduction \% with respect to positive controls, of different concentrations of ciprofloxacin-loaded NPS (abbreviated as "C+") and blank NPs (abbreviated as "C-") $(n=3)$. $* p<0.01, * * * p<0.0001$, ${ }^{\#} p<10^{-6}$. a PLGA NPs. b PLGAwow NPs. $\mathbf{c}$ PCL NPs. $\mathbf{d}$ Comparison of all ciprofloxacinloaded NPs a

Metabolic activity of hMSCs

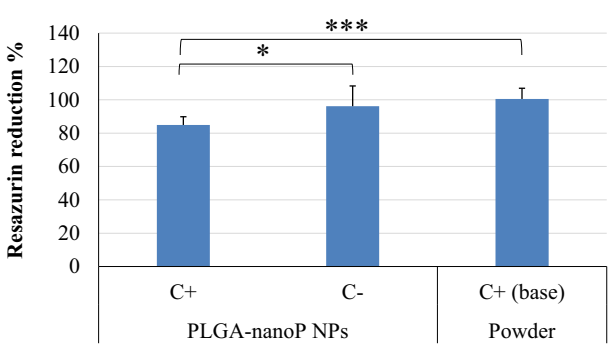

C

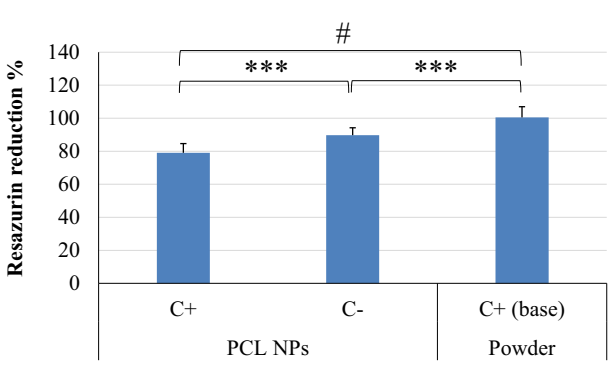

b

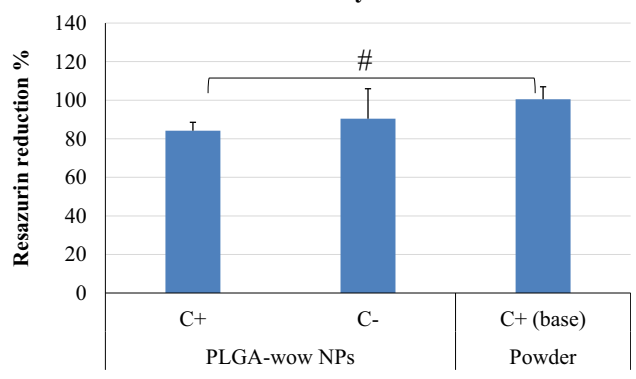

d

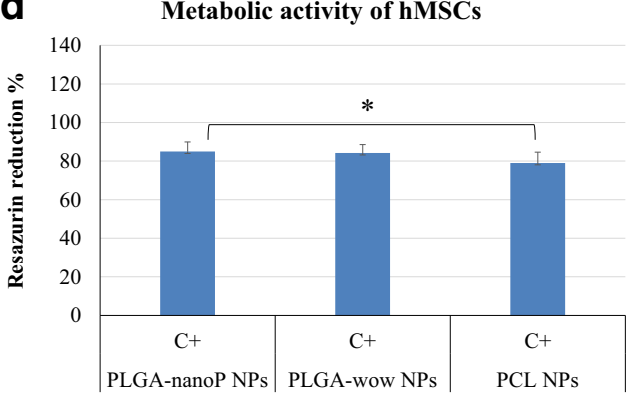

\section{Conclusion}

In many tissue engineering applications, the role of the scaffold is to support tissue regeneration, which comes after reconstructive surgery in a hostile microenvironment, in which inflammation is present, together with high probability of infection relapses. Depending on the extent of damage, the performance of the scaffolds might remain
Fig. 11 Phalloidin (green channel) and DAPI (blue channel) staining confirming the homogeneous growth and proliferation of human mesenchymal stromal cells (hMSCs) on electrospun (ES) scaffolds with and without ciprofloxacin-loaded PLGA NPs. The cells were cultured and imaged at 24-h and 8-day time points. Scale bar $=200 \mu \mathrm{m}$

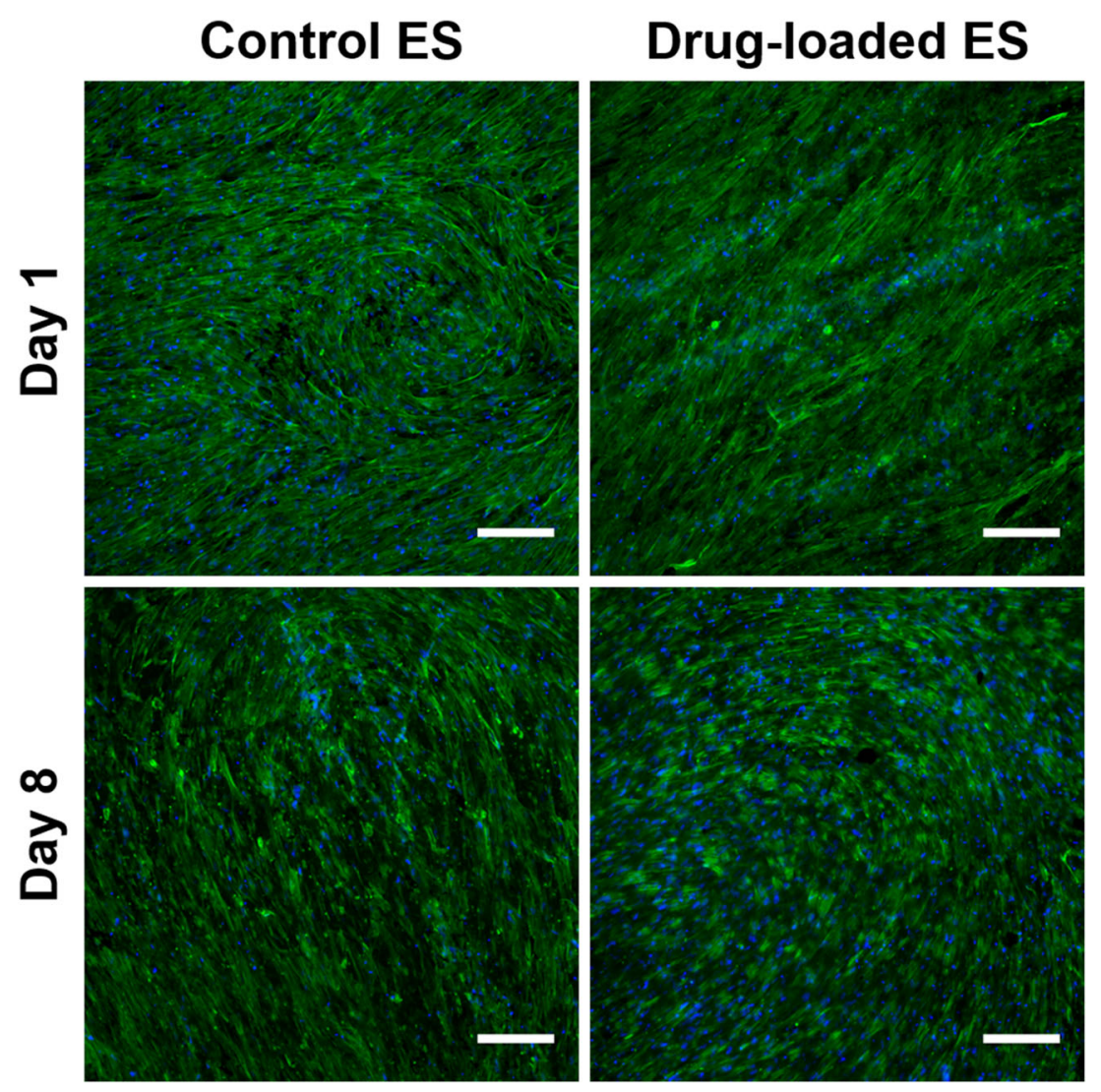


Fig. 12 S. aureus inhibition test at different ciprofloxacin $(\mathrm{C}+)$ concentrations $(0.2-200 \mu \mathrm{g} / \mathrm{ml})$

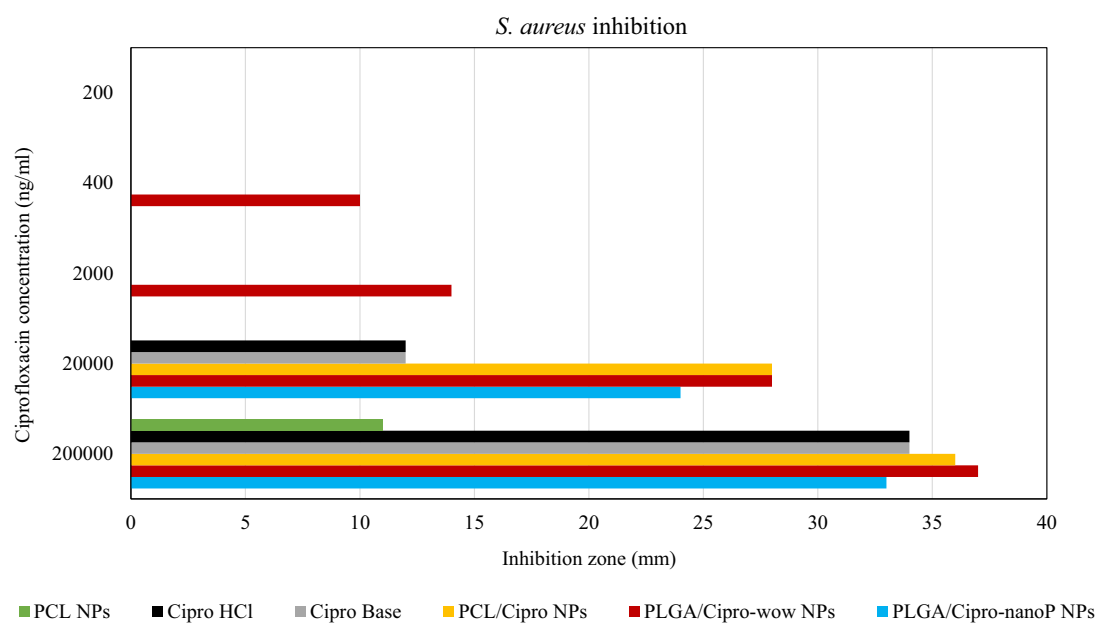

suboptimal, which makes it difficult to recover suitable functionality. Here-presented antibiotic-loaded polymeric NPintegrated electrospun nanofibers aim at filling the treatment gap by providing biomimetic, reliable, and highly effective scaffolds with sustained drug delivery and anti-inflammatory activity.

Results showed that ciprofloxacin-loaded PLGA and PCL NPs were successfully prepared by two different manufacturing strategies where a continuous manufacturing method which offers unlimited scale-up was employed. Prepared particles showed high EE\% and a narrow particle size distribution, which are critical for clinical applicability, among which PCL NPs and PLGA-wow NPs were selected as potential candidates owing to better stability. Prepared particles showed predictable controlled release properties, which would enable sustaining the antibiotic concentration at the site of action for enhancing the therapy. Additionally, all the NPs were more effective and safer against $S$. aureus and $P$. aeruginosa in comparison to free drug. This finding suggests that the developed particles can be employed to reduce the applied dose and eventually minimize the oral or i.v. administration of antibiotics after implants, since they offer local drug delivery as they are embedded in electrospun fibers.

The current work shows that there is good potential for application of antibiotic-loaded NP-embedded nanofiber scaffolds for first-line therapy of tissue engineering. The results indicate that antibiotic-loaded NPs can be successfully applied for use of scaffolds to deliver antibiotics locally for preventing bacterial infections around the implant. The ciprofloxacinloaded NPs in electrospun scaffolds offer a better profit for the therapy since such an approach offers the treatment and/or prevention of infection by bacteria after implanting in comparison to the traditional implants. Presented data provides solid scientific evidence for fulfilling the requirements of local nano antibiotic delivery systems with biodegradability and biocompatibility for a wide range of tissue engineering and regenerative medicine applications, including tympanic ear membranes. Further characterization of such systems, including in vivo studies, is required to ensure successful transfer from lab to clinical applications.
Fig. $13 P$. aeruginosa inhibition test at different ciprofloxacin $(\mathrm{C}+)$ concentrations $(0.2-200 \mu \mathrm{g} / \mathrm{ml})$

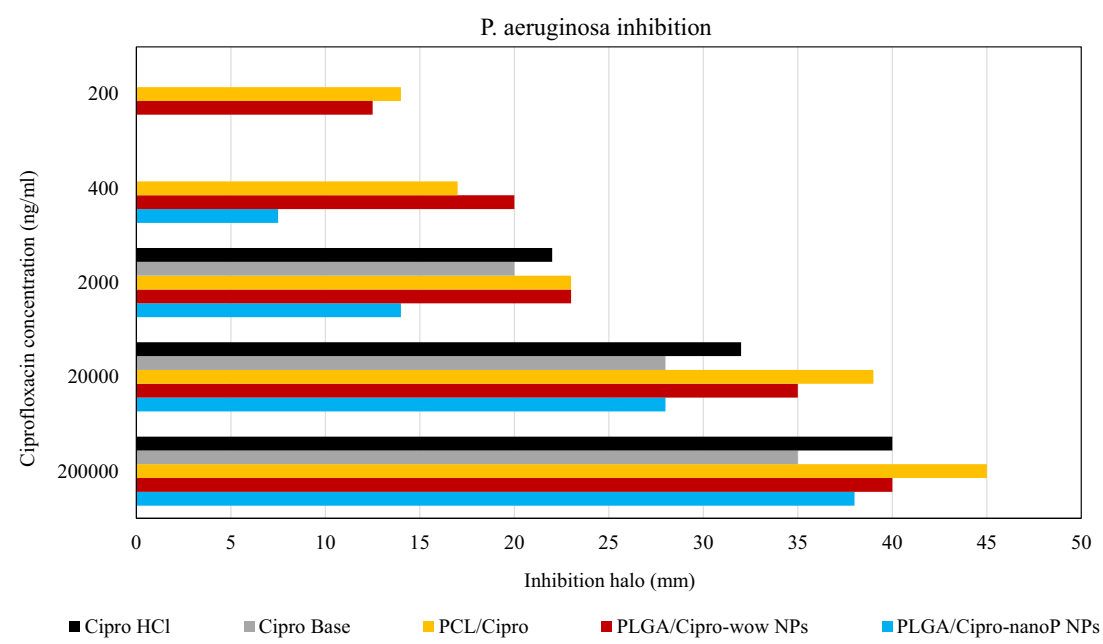



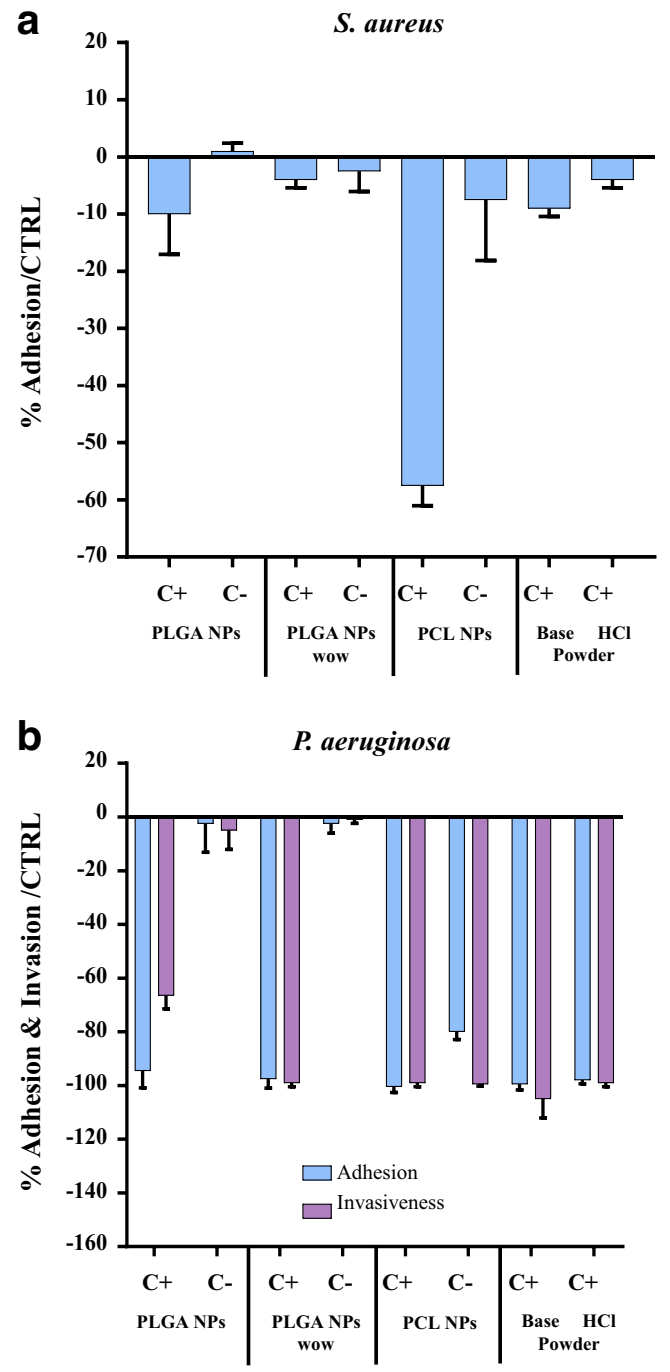

Fig. 14 Adhesiveness and invasiveness of $S$. aureus - and P. aeruginosainfected HaCaT cells using ciprofloxacin-loaded $(\mathrm{C}+)$ and unloaded $(\mathrm{C}-)$ NPs. a $S$. aureus adhesion. b $P$. aeruginosa adhesion and invasiveness

This design is envisaged to stimulate in situ tissue regeneration owing to optimal tolerance, accelerated healing owing to normalized microenvironment without inflammatory components or bacteria. Patients' quality of life could be remarkably improved upon implementation of this therapy approach.

Acknowledgments The authors would like to thank Ms. Lara Bayer for her technical assistance at MJR PharmJet GmbH labs, and Mr. Pratik Bachhav for his graphical assistance at Maastricht University.

Funding information The authors acknowledge the 4NanoEARDRM project funded under the frame of EuroNanoMed III.

\section{Compliance with ethical standards}

Conflict of interest The authors declare that they have no conflict of interest.

\section{References}

1. Patra JK, Das G, Fraceto LF, Campos EVR, Rodriguez-Torres MDP, Acosta-Torres LS, et al. Nano based drug delivery systems: recent developments and future prospects. J Nanobiotechnol. 2018;16(1):71. Available from: https://www.ncbi.nlm.nih.gov/ pubmed/30231877. Accessed Jan 2020.

2. Goyal R, Macri LK, Kaplan HM, Kohn J. Nanoparticles and nanofibers for topical drug delivery. J Control Release. 2016;240:77-92. Available from: http://www.sciencedirect.com/science/article/pii/ S0168365915302157. Accessed Jan 2020.

3. Ulbrich K, Hola K, Subr V, Bakandritsos A, Tucek J, Zboril R. Targeted drug delivery with polymers and magnetic nanoparticles: covalent and noncovalent approaches, release control, and clinical studies. Chem Rev. 2016;116(9):5338-431.

4. Langer R, Vacanti JP. Tissue engineering. Science. 1993;260(5110): 920-6.

5. Moroni L, Boland T, Burdick JA, De Maria C, Derby B, Forgacs G, et al. Biofabrication: a guide to technology and terminology. Trends Biotechnol. 2018;36(4):384-402. Available from: http://www. sciencedirect.com/science/article/pii/S0167779917302792. Accessed Jan 2020.

6. Choudhury D, Anand S, Naing MW. The arrival of commercial bioprinters - towards 3D bioprinting revolution! Int J Bioprinting. 2018;4(2). https://doi.org/10.18063/ijb.v4i2139 Available from: http://ijb.whioce.com/index.php/int-j-bioprinting/article/view/139. Accessed Jan 2020.

7. Dersch R, Graeser M, Greiner A, Wendorff JH. Electrospinning of nanofibres: towards new techniques, functions, and applications. Aust J Chem. 2007;60(10):719-28. https://doi.org/10.1071/ $\mathrm{CH} 07082$

8. Bhardwaj N, Kundu SC. Electrospinning: a fascinating fiber fabrication technique. Biotechnol Adv. 2010;28(3):325-47.

9. Danti S, Mota C, D'alessandro D, Trombi L, Ricci C, Redmond SL, et al. Tissue engineering of the tympanic membrane using electrospun PEOT/PBT copolymer scaffolds: a morphological in vitro study. Hear Balanc Commun. 2015;13(4):133-47. https:// doi.org/10.3109/21695717.2015.1092372.

10. Mota C, Danti S, D’Alessandro D, Trombi L, Ricci C, Puppi D, et al. Multiscale fabrication of biomimetic scaffolds for tympanic membrane tissue engineering. Biofabrication. 2015;7(2):25005.

11. Sundaramurthi D, Krishnan UM, Sethuraman S. Electrospun nanofibers as scaffolds for skin tissue engineering. Polym Rev. 2014;54(2):348-76. https://doi.org/10.1080/15583724.2014. 881374.

12. Alves da Silva ML, Martins A, Costa-Pinto AR, Costa P, Faria S, Gomes M, et al. Cartilage tissue engineering using electrospun PCL nanofiber meshes and MSCs. Biomacromolecules. 2010;11(12): 3228-36.

13. Wang Z, Wang Z, Lu WW, Zhen W, Yang D, Peng S. Novel biomaterial strategies for controlled growth factor delivery for biomedical applications. NPG Asia Mater. 2017;9(10):e435. https://doi. org/10.1038/am.2017.171.

14. Sakai R, John B, Okamoto M, Seppälä JV, Vaithilingam J, Hussein $\mathrm{H}$, et al. Fabrication of polylactide-based biodegradable thermoset scaffolds for tissue engineering applications. Macromol Mater Eng. 2013;298(1):45-52. https://doi.org/10.1002/mame.201100436.

15. Prabaharan M, Sivashankari PR. Prospects of bioactive chitosanbased scaffolds in tissue engineering and regenerative medicine BT - chitin and chitosan for regenerative medicine. In: Dutta PK, editor. . New Delhi: Springer India; 2016. p. 41-59. https://doi.org/ 10.1007/978-81-322-2511-9 2.

16. Malafaya PB, Silva GA, Reis RL. Natural-origin polymers as carriers and scaffolds for biomolecules and cell delivery in tissue engineering applications. Adv Drug Deliv Rev. 2007;59(4-5):207-33. 
17. O'Brien FJ. Biomaterials \& scaffolds for tissue engineering. Mater Today. 2011;14(3):88-95. Available from: http://www. sciencedirect.com/science/article/pii/S136970211170058X. Accessed Jan 2020.

18. Nagarajan S, Bechelany M, Kalkura NS, Miele P, Bohatier CP, Balme S. Chapter 20. Electrospun nanofibers for drug delivery in regenerative medicine. In: Mohapatra SS, Ranjan S, Dasgupta N, Mishra RK, Thomas SBT-A of TND and DS, editors. Micro and nano technologies. Elsevier; 2019. p. 595-625. Available from: http://www.sciencedirect. com/science/article/pii/B978012814029100020X. Accessed Jan 2020.

19. Babitha S, Rachita L, Karthikeyan K, Shoba E, Janani I, Poornima $\mathrm{B}$, et al. Electrospun protein nanofibers in healthcare: a review. Int J Pharm. 2017;523(1):52-90.

20. Buck E, Maisuria V, Tufenkji N, Cerruti M. Antibacterial properties of PLGA electrospun scaffolds containing ciprofloxacin incorporated by blending or physisorption. ACS Appl Bio Mater. 2018;1(3): 627-35. https://doi.org/10.1021/acsabm.8b00112.

21. Xu X, Zhong W, Zhou S, Trajtman A, Alfa M. Electrospun PEGPLA nanofibrous membrane for sustained release of hydrophilic antibiotics. J Appl Polym Sci. 2010;118(1):588-95. https://doi. org/10.1002/app.32415.

22. Qi R, Guo R, Zheng F, Liu H, Yu J, Shi X. Controlled release and antibacterial activity of antibiotic-loaded electrospun halloysite/ poly(lactic-co-glycolic acid) composite nanofibers. Colloids Surfaces B Biointerfaces. 2013;110:148-55. Available from: http://www.sciencedirect.com/science/article/pii/ S0927776513002944. Accessed Jan 2020.

23. Zhang Z, Tang J, Wang H, Xia Q, Xu S, Han CC. Controlled antibiotics release system through simple blended electrospun fibers for sustained antibacterial effects. Vol. 7, ACS Applied Materials \& Interfaces. United States; 2015. p. 26400-4.

24. Vinatier C, Guicheux J. Cartilage tissue engineering: from biomaterials and stem cells to osteoarthritis treatments. Ann Phys Rehabil Med. 2016;59(3):139-44. Available from: http://www. sciencedirect.com/science/article/pii/S187706571630001X. Accessed Jan 2020.

25. Qu H, Fu H, Han Z, Sun Y. Biomaterials for bone tissue engineering scaffolds: a review. RSC Adv. 2019;9(45):26252-62. https://doi. org/10.1039/C9RA05214C.

26. Günday Türeli N, Türeli AE, Schneider M. Optimization of ciprofloxacin complex loaded PLGA nanoparticles for pulmonary treatment of cystic fibrosis infections: design of experiments approach. Int J Pharm. 2016;515(1):343-51. Available from: http://www. sciencedirect.com/science/article/pii/S0378517316309590. Accessed Jan 2020.

27. Draheim C, de Crecy F, Hansen S, Collnot E-M, Lehr C-M. A design of experiment study of nanoprecipitation and nano spray drying as processes to prepare PLGA nano- and microparticles with defined sizes and size distributions. Pharm Res. 2015;32(8):2609-24.

28. Havel H, Finch G, Strode P, Wolfgang M, Zale S, Bobe I, et al. Nanomedicines: from bench to bedside and beyond. AAPS J. 2016;18(6):1373-8

29. Caster JM, Patel AN, Zhang T, Wang A. Investigational nanomedicines in 2016: a review of nanotherapeutics currently undergoing clinical trials. Wiley Interdiscip Rev Nanomed Nanobiotechnol. 2017;9(1).

30. Ventola CL. Progress in nanomedicine: approved and investigational nanodrugs. P T. 2017;42(12):742-55. Available from: https:// www.ncbi.nlm.nih.gov/pubmed/29234213. Accessed Jan 2020.

31. Primavessy D, Günday Türeli N, Schneider M. Influence of different stabilizers on the encapsulation of desmopressin acetate into PLGA nanoparticles. Eur J Pharm Biopharm. 2017;118:48-55. Available from: http://www.sciencedirect.com/science/article/pii/ S0939641116309638. Accessed Jan 2020.

32. Soppimath KS, Aminabhavi TM, Kulkarni AR, Rudzinski WE. Biodegradable polymeric nanoparticles as drug delivery devices. J Control Release. 2001;70(1-2):1-20.
33. Günday Türeli N, Türeli AE. Good manufacturing practices (GMP) of magnetic nanoparticles. In: Thanh NTK, editor. Clinical applications of magnetic nanoparticles. Boca Raton London New York: CRC Press, Taylor and Francis; 2018. p. 473-82.

34. Wacker M. Nanocarriers for intravenous injection - the long hard road to the market. Int J Pharm. 2013;457(1):50-62.

35. Torge A, Wagner S, Chaves PS, Oliveira EG, Guterres SS, Pohlmann AR, et al. Ciprofloxacin-loaded lipid-core nanocapsules as mucus penetrating drug delivery system intended for the treatment of bacterial infections in cystic fibrosis. Int J Pharm. 2017;527(1):92-102. Available from: http://www.sciencedirect.com/science/article/pii/ S0378517317304234. Accessed Jan 2020.

36. Günday Türeli N, Torge A, Juntke J, Schwarz BC, Schneider-Daum N, Türeli AE, et al. Ciprofloxacin-loaded PLGA nanoparticles against cystic fibrosis P. aeruginosa lung infections. Eur J Pharm Biopharm. 2017;117:363-71 Available from: http://www. sciencedirect.com/science/article/pii/S0939641116309924. Accessed January, 2020.

37. Zhu Z, Anacker JL, Ji S, Hoye TR, Macosko CW, Prud'homme RK. Formation of block copolymer-protected nanoparticles via reactive impingement mixing. Langmuir. 2007;23(21):10499-504.

38. Zhao C-X, He L, Qiao SZ, Middelberg APJ. Nanoparticle synthesis in microreactors. Chem Eng Sci. 2011;66(7):1463-79. Available from: http://www.sciencedirect.com/science/article/pii/ S0009250910005142. Accessed Jan 2020.

39. Goyal U, Arora R, Aggarwal G. Formulation design and evaluation of a self-microemulsifying drug delivery system of lovastatin. Acta Pharma. 2012;62(3):357-70.

40. Gunday Tureli N, Tureli AE, Schneider M. Counter-ion complexes for enhanced drug loading in nanocarriers: proof-of-concept and beyond. Int J Pharm. 2016;511(2):994-1001.

41. Brannon-Peppas L. Recent advances on the use of biodegradable microparticles and nanoparticles in controlled drug delivery. Int J Pharm. 1995;116(1):1-9. Available from: http://www.sciencedirect.com/ science/article/pii/037851739400324X. Accessed Jan 2020.

42. Filkins LM, O'Toole GA. Cystic fibrosis lung infections: polymicrobial, complex, and hard to treat. PLoS Pathog. 2015;11(12):e1005258. Available from: https://www.ncbi.nlm. nih.gov/pubmed/26719892. Accessed Jan 2020.

43. Pichichero ME. Otitis media. Pediatr Clin N Am. 2013;60(2):391407.

44. Kumari A, Yadav SK, Yadav SC. Biodegradable polymeric nanoparticles based drug delivery systems. Colloids Surf B Biointerfaces. 2010;75(1):1-18.

45. Sinha VR, Bansal K, Kaushik R, Kumria R, Trehan A. Poly-ecaprolactone microspheres and nanospheres: an overview. Int $\mathrm{J}$ Pharm. 2004;278(1):1-23. Available from: http://www. sciencedirect.com/science/article/pii/S0378517304001693. Accessed Jan 2020.

46. Woodruff MA, Hutmacher DW. The return of a forgotten polymerpolycaprolactone in the 21st century. Prog Polym Sci. 2010;35(10): 1217-56. Available from: http://www.sciencedirect.com/science/article/ pii/S0079670010000419. Accessed Jan 2020.

47. Espinoza SM, Patil HI, San Martin Martinez E, Casañas Pimentel R, Ige PP. Poly- $\varepsilon$-caprolactone (PCL), a promising polymer for pharmaceutical and biomedical applications: focus on nanomedicine in cancer. Int $\mathrm{J}$ Polym Mater Polym Biomater. 2020;69(2):85-126. https://doi.org/10.1080/00914037.2018. 1539990.

Publisher's note Springer Nature remains neutral with regard to jurisdictional claims in published maps and institutional affiliations. 